\title{
Development of the Education of Open Infra BIM Based Construction Automation
}

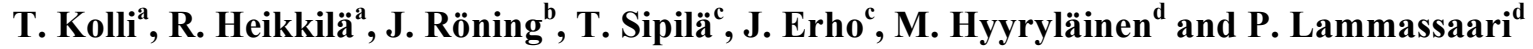

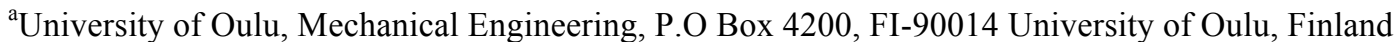 \\ ${ }^{\mathrm{b}}$ University of Oulu, Computer Science and Engineering, P.O Box 8000, FI-90014 University of Oulu, Finland \\ ${ }^{c}$ Oulu University of Applied Sciences, P.O Box 222, FI-90101 Oulu, Finland \\ ${ }^{\mathrm{d} O u l u}$ Vocational College, Asemakyläntie 5, 90840 Haukipudas, Finland \\ E-mail: tanja.kolli@oulu.fi, rauno.heikkila@oulu.fi, juha.roning@oulu.fi, terttu.sipila@oamk.fi, \\ jarmo.erho@,oamk.fi, marko.hyyrylainen@,osao.fi, pekka.lammassaari@,osao.fi
}

\begin{abstract}
-
This paper presents the results of the practical learning experience when combine three different school level students to learn open infrastructure building information modelling (infra BIM) and automation during OuluZone workshop week. Students started to build Speedway track in OuluZone test centre with one-week resources with the help of experts from industry and teachers. In addition, for students, ten different tricks were designed to present the tasks of the responsible person on the construction site. The idea of tricks was to teach students how these experts are using open infra BIM construction automation in their work. Infrakit, which is open infra BIM cloud service, was used to connect automation systems together. Based on the one-week workshop experience including questionnaire study answers and the results of pretest and exam for students, it can be concluded that this type of practical learning is an effective way to teach open infra BIM based automation to students. Keywords -
\end{abstract}

Automation, Education, Infrastructure building information modelling (infra BIM)

\section{Introduction}

The construction industry has started to found the advantages of use building information modelling (BIM) as a tool for managing the process of design, construction, and across the supply chain. The top five advantages of using BIM has found to include scheduling, communication, visualization, coordination, and clash detection [1]. The other reasons for the grow of BIM are application of technologies and innovations, which integrates the construction process not only buildings but also in infrastructures, such as transportation (roads, bridges), energy (power generation plants), utility (networks/pipelines), recreational (parks, stadiums) and environmental (managing flood and coastal defences). [2] In fact, BuildingSMART Finland has a forum which is responsible for the development of the infrastructure BIM (infra BIM). [3] However, there are still some obstacles to adopt BIM within architecture, engineering, construction, owner, and operator (AECOO) industry, such as technical barriers, legal and liability issues. Besides those, there is also is a need for training, education, and regulations [4]. BIM teaching in educational institutions will be grown due to the recommendation of European Union [5]. There are courses offered by private companies for professionals who want to update their knowledge in the field of infra BIM, or graduate as BIM coordinator, however these courses are relatively expensive. Therefore, universities and polytechnics are starting to provide BIM courses for construction and architecture students. [6]

Education in Universities and Universities of Applied Science schools is often lecture-based, instructorcentered pedagogical models. Courses can be included lectures and exercises with detailed spots. Practical knowhow about infra BIM and automation students is gained mainly from summer jobs, since the lack of money is prevented this type of practical learning from schools. However, the authors' opinion is that practical learning is vital to understand the theory as well as to learn new technologies and how to collaboration with expertise in the field. These skills can help students to find their future jobs. The idea that student can use learned information from teacher to real world challenges and problems have found to be excellent, but a challenging way to be as deep learning of the subject, and found a promising option for BIM education [7, 8]. BIM should be teaching as a process improvement methodology rather than only a technology. Giving students real word problems and active learning experiences will encourage to self-directed learning and critical thinking [9]. 
There is relatively rare any collaboration between school levels. Some articles are about the connection of courses between universities or different topics, such as BIM and sustainability $[10,11]$. The objective in OuluZone+ project (started in March 2017 and ended in December 2017), which is presented in this article, was to connect the special open BIM and automation expertise of three different educational level institutions and to utilise their resources, and to be a practical learning experience for students, as well as for teachers, too. The goal was to plan, implement and evaluate the OuluZone workshop week in OuluZone test centre. Before the one-week workshop in OuluZone test centre, the students were trained in the lectures to understand the basics open infra BIM and automation knowhow from to implement the workshop. The goal during the OuluZone workshop week was that students use their know how from lectures and build the Speedway-track with oneweek resources with the help of expertise from school and from industry. Findings and lessons learned from the practical learning experience are presented in this article.

\section{Finnish Educational Framework System}

In Finland after finishing the mandatory basic education at age of 15 , the student can select different educational paths. Infra BIM related courses offered at all levels after basic education. However, there is rarely any collaboration between the school levels.

The goal of the OuluZone+ project is to develop research, development, and education environment for open infrastructure BIM is between the institutions of The University of Oulu, the Oulu University of Applied Sciences (OAMK), and Oulu Vocational College (OSAO). These institutions are presenting the three different level that is collaborating in the OuluZone+ project.

Before the workshop week in the OuluZone test centre, students learn practical knowledge in selected courses, presented below, in each institution. Teachers are using both cognitive and behavior approach to teach BIM to students [10]. This means that the theory of BIM is learned by lectures but also from experts from industry.

For a Masters Degree students of Technology there is a five-credit course called "Information modelling and automation building construction and maintenance", at the Department of Structures and the Construction Technology Research Unit at the University of Oulu. During the course, the students are trained to learn the Novapoint boulevard program, RTK-GNSS positioning techniques, Novatron's 3D machine control system using a mini excavator, and the use of the Infrakit in the realtime control of the site. Annually, the course has an average of 10-15 graduate civil engineer students.
For engineering students at the Oulu University of Applied Sciences (OAMK) there is a five-credits course entitled "Infra BIM modeling and building a construction project". At the start of the annual course, OAMK has about 80 engineering students and 40 master students. For masters students there is a course called "Computer modeling at infrastructures". The teaching of measurement techniques has unfortunately decreased in recent years due to teacher resources, and it has been integrated more into other courses. AutoCAD Civil3D is used to teach boulevard design.

The Oulu Vocational College (OSAO) provides teaching for construction machinery and lorry drivers as well as logistics instructors. The basic education for young people is three years, with a one-year course of about 20 students; thus a total number was 60 . In addition, adult education includes some 40 students. OSAO has four different machines (three excavators and one wheel loader) on the campus of Haukipudas with Scanlaser Oy's and Novatron Oy's 3D machine control system installed in educational use. In addition, the University of Oulu maintains a Sunward mini excavator machine, where Novatron Oy's 3D machine control system, at OSAO's premises at Haukipudas. Several test simulators as in Figure 1, which estimate performance and gives feedback to the user. The test simulator is integrated into Leica's 3D machine control system so that the simulation corresponds to a truly genuine environment. The scope of the 3D Driving tutorial for construction experiments is 15 competence points.

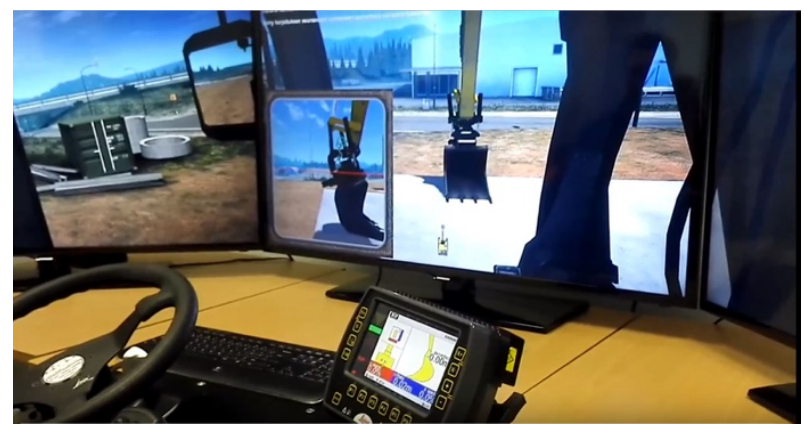

Figure 1. Test simulator (Tenstar) integrated to Leica's 3D machine control system to practice the use of excavator. 


\section{Development of the Education Workshop for Open BIM Based Construction}

\subsection{Tools for Implement Ouluzone Workshop Week}

The OuluZone test centre is a place located around 30 minutes away from the city centre of Oulu built by the City of Oulu. In OuluZone test centre, one can do activities such as motor sports, research, and education.

The OuluZone workshop week, the construction site was decided to be the Speedway track, and the beginning of its cutting operation. The geometry of Speedway-track was first done in traditional 2D drawings. The total length of the track is $437 \mathrm{~m}$ in with a straight line of $65 \mathrm{~m}$. The 3D model of the Speedway track (Figure 2) was made in Mitta in open file formats such as DXF and LandXML. It was calculated that the weight to be cut was $7848 \mathrm{~m}^{3}$, filling $7727 \mathrm{~m}^{3}$ and surplus mass $100 \mathrm{~m}^{3}$.

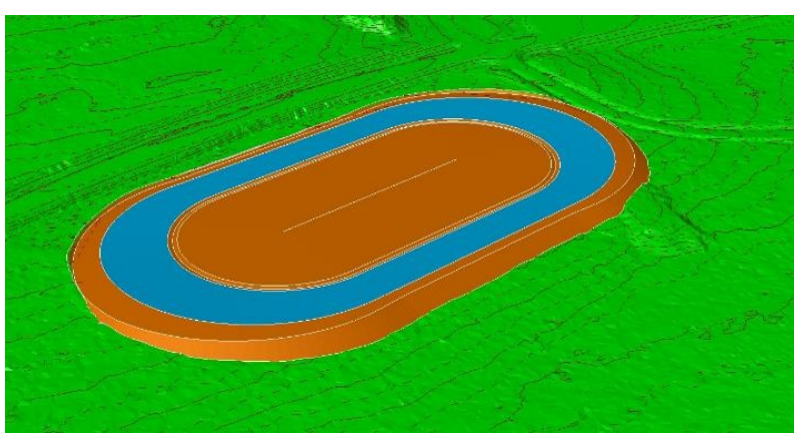

Figure 2. Speedway-track in 3D DFX format (Mitta Oy).

For practical implementation in OuluZone test centre, it was decided that OSAO brought necessary machineries and dumper trucks to start the Speedway-track building. The University of Oulu organized other necessary infra building information modelling (infra BIM) and automation technologies and systems. To support the development of education, technology companies and key infra actors were challenged to bring their technology.

Based on authors previously projects [12] and experiences Infrakit have been found to reliable. That was the reason why Infrakit (www.infrakit.fi) was used as an open infra BIM tool for real-time monitoring of Speedway-track progress and for quality checking. In addition, Infrakit can be integrated into many machine control systems such as Trimble, Topgeo, Leica Geosystems, and other software. In Figure 3. shows how different automation systems of Novatron are connected real time to Infrakit and used to share data between a designer, project owner, site foreman, machinery and surveyor. The students and teachers had an Infrakittraining day before the OuluZone workshop week. The goal of Infrakit-training was to present to the audience, how the Speedway project is set up in Infrakit. In addition, meaning coordinate systems, designed files in correct formats and other necessary information needed in the beginning of the construction site was also presented.

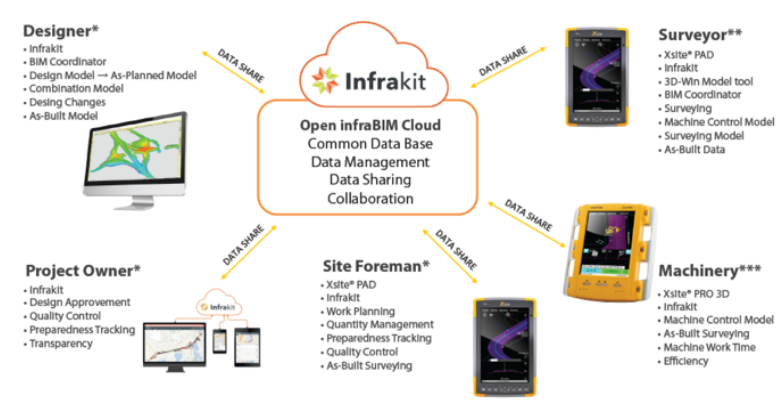

Figure 3. Automation system and operation models (Novatron Oy).

All the measurement devices, such as RTK-GNSStablet, and mobile devices, meaning the android guidance system in trucks, tablets for construction leaders, and laptops that were used on the Speedway construction site are integrated into the collaboration cloud via Infrakit internet system. The other necessary equipment needed in Speedway-track construction site were RTK-GNSSbase station, three to four pieces' reference points around the Speedway track, machines with 3D-guidance systems both Scanlaser and Novatron, Leica-robot tachometer, Trimble R10-RTK-GNSS-system with Infrakit, a video camera connection, and Drone-monitoring. In addition, there were two excavators, wheel loader, and two trucks from OSAO. 


\subsection{OuluZone Workshop Week Preparation for Students}

The OuluZone workshop week was 30 October to 2 November 2017. During this period, all the students and teachers had a common information event about the workshop days in OuluZone test centre in the University of Oulu, two working days Speedway-track contract site in OuluZone test centre, and a finally enclosing day in OAMK.

There was pre-test at the beginning of the week and end exam at enclosing day, both were based on Common Infra BIM Requirements (YIV2015) [13]. The result of the pre-test and exam was analyzed. In addition, during the enclosing day the students and teacher was answered in questionnaire study regarding: 1) what was successful, 2) how OuluZone workshop week can be developed, and finally 3 ) to give the school grade from 1 to 5 .

The amount of students was 6, 41, and 13 from the University of Oulu, OAMK and OSAO, respectively. The students from OSOA were decided to be responsible for working machines. They started two weeks earlier of the preparation of the workshop week. The students learned the basics about positioning, charting, coordination systems, and GPS measuring. These profession skill demands are part of their degree and were estimated during the workshop week.

Students from University of Oulu and OAMK were divided into 10 groups' occasional order. To students, 10 different tricks were planned:

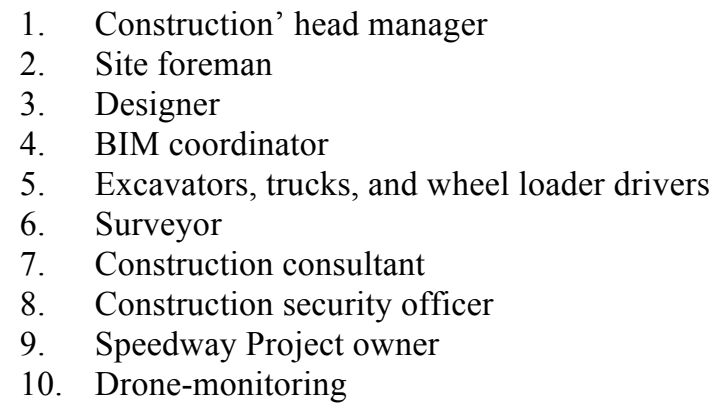

The purpose of each trick was present the tasks of the responsible person on site, and how they are using open infra BIM in their own work. The responsible person on the trick was professionals from industry (Mitta Oy, Leica GeoSystems Oy, Destia Oy, Novatron Oy, and Infrakit Oy), or were a teacher from the University of Oulu, OAMK, or OSAO. The connection of ten tricks to open infra BIM is shown in Figure 4.

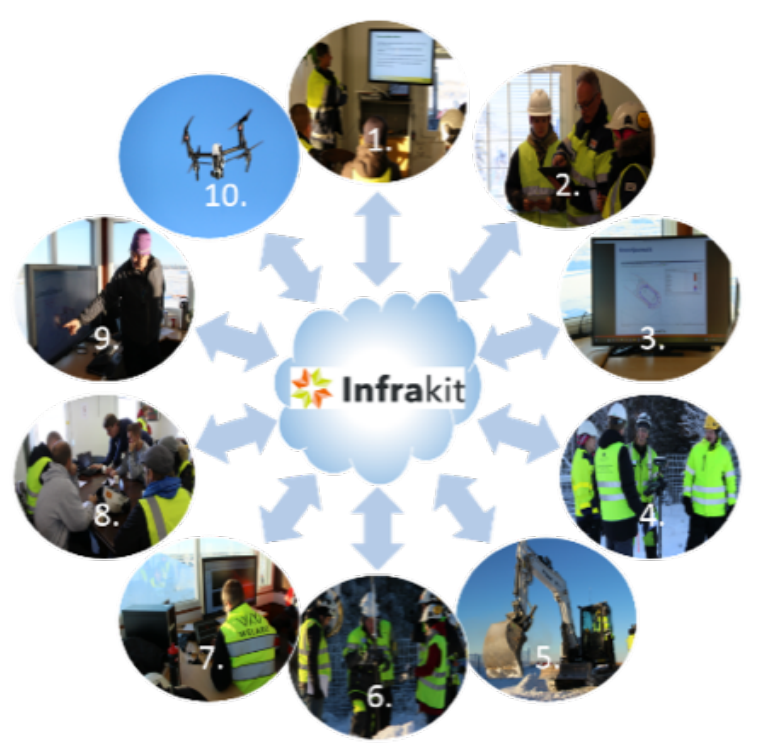

Figure 4. Ten tricks for students during the OuluZone workshop days in OuluZone test centre.

During the OuluZone workshop days, the student group visit each trick about 25 minutes. During this time, the students heard about the work of the responsible person and had a possibility to ask. Each student was to give a paper and pen to do his or her notes for example to write a report to the teacher. Transfer time one trick into other was about 10 minutes.

\subsection{Objectives to OuluZone Workshop Working Days}

The objective of the first workday in OuluZone test centre was to practice and to understand how the open infra BIM is used on Speedway track site. The following things are expected of students to learn:

- How is the map of the Speedway track site, machine control system and realization measuring recorded?

- How can all the experts on the Speedway track site communicate each other in real time and do changes if needed?

- How is the schedule of the Speedway track, and the calculation of masses done based on the model?

- How the information from Scanlaser's or Novatron's Guiding 3D systems in excavators can be used for the controlling?

- How is the quality check of the excavator done by measuring the cutting surfaces continuously?

- What is the reason to measure separate "point of reference" of RTK-GNSS systems?

- What is the reason to use Drone-plane to follow and control the progress of the construction site? 
The objective of the second workday in OuluZone test centre was the automation change and problem scenarios. The aim was for the student to understand why the information model needs to be monitored and why it must react whenever possible changes occur. The following possible problem scenarios were planned and what must be done:

- The excavator is excavated (intentionally) $10 \mathrm{~cm}$ too deep. The actual point is stored, whereby the error should be detected by the Infrakit system (supervisor) and reacted to it or interrupted the excavation

- Adding a drum scraper model to the excavator machine control system. The background map shows it. The driver and the manager should observe it and ask for this model from the site manager who request a template from a road designer.

- Some layer thickness is incorrectly a type cross section; the automation operator should note and request a repair from the designer, or be repaired by the automation operator.

- The excavator driver $\mathrm{x}$ reports the observed rock surface and asks the job director for blasting operations.

- A person appears on site without any safety equipment. The supervisor suspends the work situation, removes the person and orders the contractor for the sanction.

- Failure of the vehicle and the working machine, condition check, etc.

\section{Results and Discussion}

At the beginning of the OuluZone workshop week, the students were given a simple pre-test based on Common Infra BIM Requirements (YIV2015). The pretest contained 10 question and there were four answer options in each question. The pre-test was given to Monday and the answers were collected next day. The correct answers were told after the students' answers was given. Of 32 results, the average degree was 6.34 with the standard deviation 3.08 (Figure 5). The result indicates that students were learned something about the infra BIM during the lectures.

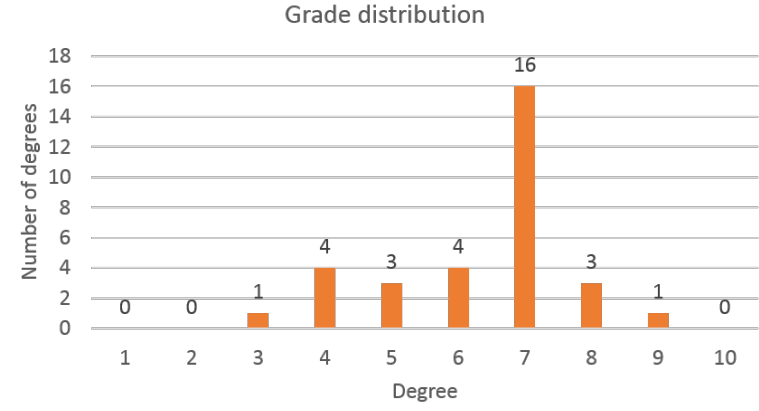

Figure 5. The 32 result of pre-test the average degree was 6.34 by the standard deviation 3.08.

During two OuluZone workshop days, the team of five to six students was visiting ten different tricks. The first day was training and the second day focused on the solving problems. Students were heard more how the experts were using Infrakit in their job function. Construction head manager (trick 1) explained how he is using Infrakit to budgeting, scheduling, and quality control. His responsibility is also the orientation of the workers on the construction site. The site foreman (trick 2) explained to students what responsibilities it is needed to keep high quality on the site based on YIV2015. Designer (trick 3) collected and checked the Speedwaymodel and delivered those files in Infrakit. He also controls and updates the machine 3D-guidance systems. One task for students was to calculate the quantity of masses if a blasting job was needed. BIM-coordinator (trick 4) explained to students why separate RTK-GNSS systems was needed and why "the point of references" was done. He also showed how the calibration of the guidance system was done. The excavator driver (trick 5) showed the student how the Scanlaser guidance system was used when cutting process is going on. The driver also showed how the quality check was done by measuring the cutting surfaces continuously. The job of the surveyor (trick 6) was to measure and maintain reference points and safe the collected data to Infrakit. The construction consultant (trick 7) also used power point slides to explain more detail their work, and what must be considered scheduling and budgeting. Examples of real problems how heavy rain can stop the construction site was explained. The construction security officer (trick 8) showed in the first day relevant video about safety issues in the construction site. The next day, the student's task was to point out errors and give solutions to solve the problem. The Speedway Project owner (trick 9) followed the project via Infrakit. He also used drone monitoring (trick 10), especially the schedule and mass control. Figure 6 presents students visiting tricks 5 and 6 to learn more about how to measure "the point of 
reference" and the 3D machine control systems of Scanlaser and Novatron in excavators.

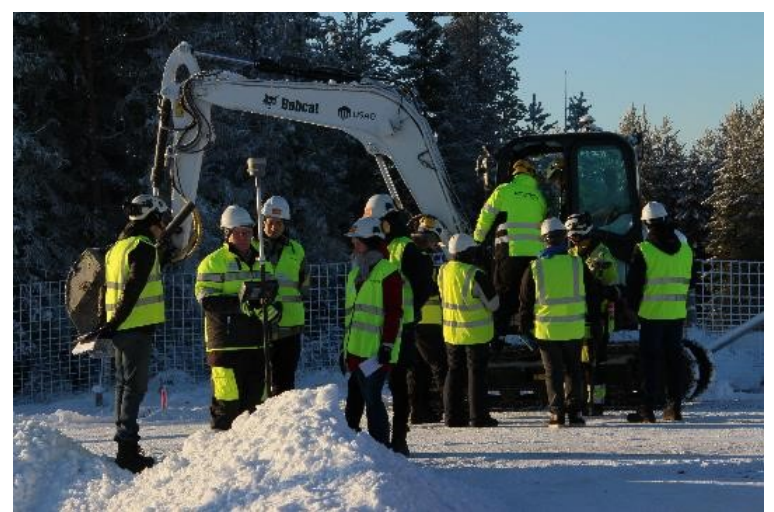

Figure 6. Trimble R10-RTK-GNSS-system (trick 6) and Bobcat excavator with both 3D-guidance systems of Scanlaser and Novatron (trick 5).

The students were possibility to ask questions and do some tasks during their visits in tricks. The communication between experts was done via chat service in Infrakit, but also mobile phone, and face-toface meeting. The students followed the Speedway site progress and saw the progress of the site, and how it was recorded into Infrakit in real-time (Figure 7).

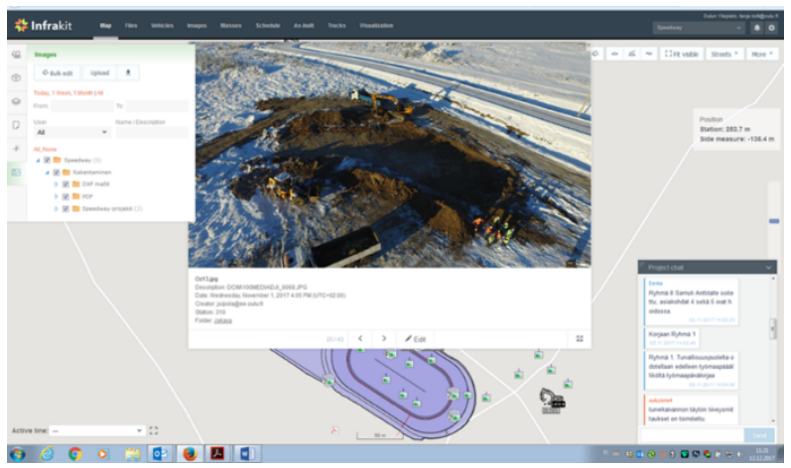

Figure 7. Speedway project in Infrakit. Pictures from Drone-plane (trick 10) are recorded and thus the site can be monitor in real-time for example in mobile application.

During the workshop days, the teachers and the experts were evaluated the student groups based on their activity and spontaneous. The level of groups was variable. Some groups were relatively silent and as opposite, there were relatively good groups. Students were not informed of the evaluation, which could explain the difference between groups. There was no competition.
The last day of workshop week was the event for discussion and feedback. Similar type of exam than the pre-test was for students. The students were not informed of the exam, so they could not be prepared themselves for it. Based on 49 results returned it can be said that the degrees were higher than pre-test degrees (Figure 8). This time, the average degree was 7.67 with the standard deviation 2.63 .

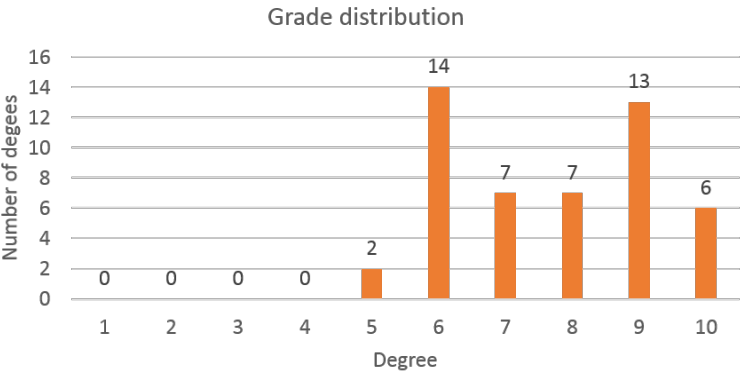

Figure 8. The 49 result of exam of final day. The average degree was 7.67 by the standard deviation 2.63 .

Feedback from students, teachers and experts was collected during the enclosing with day questionnaire study. In addition, a questionnaire in e-mail was used, since most of the experts did not have time to participate in enclosing day. Based on the answers of the questionnaire studies, the successful thing during the workshop was the collaboration between the students of University of Oulu and OAMK. The students worked and motivated each other. The students think that the experts brought much more information on different situations on working life, skills versatility, advice, and new perspectives. In addition, the reason why in the construction site is needed so many expertise was clarified.

There were also things what should be developed for the next OuluZone workshop week. Since the OuluZone workshop week was organized the first time, it was rather difficult to estimate how much time is enough on each trick. Some of the tricks can be merged together and some other can give more time. Infrakit was acting a major role during the workshop, however some students think that the information obtained was repeating itself. Maybe next time it would be a good idea to give some small tasks like budgeting or calculation. However, it must be sure that students are learned those before workshop and tested their skills during the workshop.

Based on the 49 questionnaire study answer, it can be stated that overall the whole experience was successful. Overall the grade from the first workshop was 3.42/5 the standard deviation 3.56. For the reason for good 
experience from this first OuluZone workshop week, it has been decided to continue to organize OuluZone workshop week in year the 2018, too. Based on the feedback, the workshop week is changes so that there will be three working days instead of two. During the first two days, students will be trained to take the charge of the Speedway-track construction site under the supervisor. The idea is for motive students to learn open infra BIM and automation to take subject seriously.

\section{Conclusion}

In this article, it is reported the results from the OuluZone workshop week. Students from three different levels i.e. University of Oulu, Oulu University of Applied Sciences (OAMK), and Oulu Vocational College (OSAO) were guided through open infra BIM based Speedway construction automation with the help of the experts from industry and teachers.

During the OuluZone workshop days, students learned by doing what are the tasks of the responsible person on the construction site, and how they are using open infra BIM and automation. In addition, the problem solving on the construction site was found to be an interesting way to learn in collaboration of other students and experts of industry and teachers. Based on the gained feedback, this type of practical workshop was an excellent way to bring novel knowhow from industry to improve education in courses.

Therefore, it can be concluded based on the results of pre-test and final exam as well as questioner study that practical learning is an effective way to teach open infra BIM based construction automation for students. The collaboration between three school levels will be continued in next improved OuluZone workshop week in the year 2018 .

\section{Acknowledgements}

The authors would like to acknowledgement all the students and teachers from University of Oulu, Oulu University of Applied Science (OAMK), and Oulu Vocational College (OSAO) that took the courses and participating to OuluZone workshop week. Authors are grateful to the experts from industry Mitta Oy, Destia Oy, Infrakit Oy, Welado Oy, OuluZone Operointi Oy, Novatron Oy, and Leica GeoSystems Oy, for provided the feedback on their experiences and for brought their technology. BusinessOulu is also acknowledged for their great support on this workshop. This OuluZone+ project was financed by European Regional Development Fund (A71660). Finally, the BIM4PLACEMENT ERASMUS+ project (2016-1-IT0-KA202-005399) has had a great importance of the success of the project and this paper.

\section{References}

[1] Bradley A., Li H., Lark R. and Dunn S. BIM for Infrastructure: An Overall Review and Constructor perspective. Automation in Construction, 71:139152,2016

[2] Farnsworth C.B., Beveridge S., Miller K.R. and Christofferson J.P. Application, Advantages, and Methods Associated with Using BIM in Commercial Construction. International Journal of Construction Education and Research, 11:218-236, 2015.

[3] Elmualim A. and Gilder J. BIM: Innovation in Design Management, Influence and Challenges of Implementation. Architectural Engineering and Design Management, 10:183-199, 2014.

[4] Building SMARTFinland: A Forum for BIM Collaboration, INFRA, On-line: https://buildingsmart.fi/en/infrabim-en/, Accessed: 07/03/2018.

[5] Adamu Z.A. and Thorpe T. How Universities are teaching BIM: A Review and Case Study from the UK. Journal of Information Technology in Construction, 21:119-139, 2016.

[6] McAuley B., Hore A. and West R. BIM Innovation Capability Programme (BICP). Irish BIM Study, Irish Building Magazine, 4: 78-81, 2016.

[7] Wu W. and Hyatt B. Experiential and Project-Based Learning in BIM for Sustainable Living with Tiny Solar Houses. Procedia Engineering, 145:579-586, 2016.

[8] Puolitaival T. and Forsythe P. Practical Challenges of BIM Education. Structural Survey, 34(4/5):351366, 2016

[9] Leite F. Project-Based Learning in a Building Information Modelling for Construction Management Course. Journal of Information Technology in Constructions, 21:164-176, 2016.

[10] Peterson F., Hartmann T., Fruchter R. and Fischer M. Teaching Construction Project Management with BIM Support: Experience and lesson learned. Automation in Construction, 20: 115-125, 2011.

[11] Luo Y. Sustainable Design with BIM Facilitation in Project-based Learning. Procedia engineering, 118:819-826, 2015.

[12] Kivimäki, T. and Heikkilä, R. Infra BIM based Real-time Quality Control of Infrastructure Construction Projects. In Proceedings of the International Symposium on Automation and Robotics in Construction and Mining (ISARC), 32:1-6, Oulu, Finland, 2015.

[13] BuildingSMART Finland. Common InfraBIM Requirements YIV 2015. On-line: https://buildingsmart.fi/en/infrabim-en/commoninfrabim-requirements-yiv-2015/, Accessed: 07/03/2018. 